\title{
Effector proteins of extracellular fungal plant pathogens that trigger host resistance
}

\author{
Ann-Maree Catanzariti ${ }^{\mathrm{A}}$ and David A. Jones ${ }^{\mathrm{A}, \mathrm{B}}$ \\ A Division of Plant Science, Research School of Biology, RN Robertson Building (46), The Australian \\ National University, Canberra, ACT 0200, Australia. \\ ${ }^{B}$ Corresponding author. Email: david.jones@anu.edu.au
}

\begin{abstract}
An understanding of the molecular mechanisms that plant pathogens use to successfully colonise host tissue can be gained by studying the biological activity of pathogen proteins secreted during infection. Several secreted 'effector' proteins with possible roles in virulence have been isolated from extracellular fungal pathogens, including three that have been shown to negate host defences. In most cases, significant effector variation is observed between different pathogen isolates, driven by the recognitional capacity of disease resistance proteins arrayed against the pathogen by the host plant. This review summarises what is known about the expression, function and variation of effectors isolated from extracellular fungal pathogens.
\end{abstract}

Additional keywords: avirulence, effector-triggered immunity, hypersensitive response, plant disease resistance, virulence.

\section{Introduction}

Microbial plant pathogens secrete proteins (effectors) to acquire nutrients and modulate plant defences in order to successfully invade and colonise host tissue. To counter this attack, plants have evolved resistance $(\mathrm{R})$ proteins for the recognition of specific pathogen effectors, resulting in a plant defence response known as effector-triggered immunity (ETI). Thus, effector proteins that have evolved to conduct virulence functions can themselves become recognition factors and, consequently, alteration or loss of effector genes enables pathogens to circumvent detection. This creates an ongoing evolutionary battle of attack and counter-attack. The recognition of effectors by $\mathrm{R}$ proteins occurs both directly through physical contact and indirectly via specific changes in the host cell due to the action of the effector (Caplan et al. 2008). However, regardless of the mechanism, a recognition event renders the pathogen unable to cause disease and, thus, effectors that activate ETI are termed avirulence (Avr) proteins. This review deals specifically with effector proteins from extracellular fungal pathogens that activate ETI. A summary of these proteins is given in Table 1.

Extracellular fungal pathogens colonise the intercellular spaces of host tissue - either in the apoplast surrounding parenchyma cells or the lumen of xylem vessels - but do not penetrate host cell walls to form feeding structures. Effectors secreted from this group of pathogens have been isolated largely from the apoplastic fluid or xylem sap of infected tissue; their corresponding genes have been cloned by reverse genetics. These effectors are small and generally cysteine-rich, which is consistent with the formation of intramolecular disulfide bonds, which provide stability in protease-rich environments. They are highly expressed in planta but often show little or no expression in vitro and are frequently unique proteins with no sequence similarity to proteins of known function. Although many of these effectors have been found to confer a fitness advantage, the actual virulence function has been determined for only three effectors and in each case the effector is involved in the suppression or avoidance of host defences.

\section{Cladosporium fulvum}

One of the best studied extracellular fungal plant pathogens is the tomato leaf mould fungus Cladosporium fulvum. This foliar pathogen penetrates the leaf surface through stomata and grows within the apoplast (Fig. 1). To date, eight C. fulvum proteins secreted into the apoplast have been shown to function as avirulence determinants. These have been divided into two groups: (i) race-specific Avr proteins and (ii) extracellular proteins (Ecps), which are found in all strains of C. fulvum that have been examined. The Ecp effectors (Ecp1, Ecp2, Ecp4 and Ecp5) are recognised in tomato lines carrying cognate $C f-E c p$ genes (Laugé et al. 1997; Lauge et al. 2000; de Kock et al. 2005); however, these R genes have not yet been cloned. Each Ecp locus appears to be highly monomorphic among C. fulvum isolates. This is thought to reflect a lack of selection pressure, given that $C f-E c p$ genes have not been used in commercial tomato cultivars (Stergiopoulos et al. 2007). The function of these Ecp effectors is currently unknown; however, pathogenicity tests showed that mutated strains of $C$. fulvum lacking Ecp1 or Ecp2 were less virulent than their wild-type counterpart (Laugé et al. 1997). Recently, three Ecp2 homologues were identified in Mycosphaerella fijiensis, a fungus that causes black Sigatoka disease of banana (Stergiopoulos et al. 2010). One of these homologues 
Table 1. Effector proteins identified from extracellular fungal plant pathogens that are known Avr determinants

\begin{tabular}{|c|c|c|c|c|c|}
\hline \multirow[t]{2}{*}{ Effector } & \multicolumn{2}{|c|}{ Protein size (aa) } & \multirow[t]{2}{*}{ Cys no. ${ }^{\mathrm{A}}$} & \multirow[t]{2}{*}{ Function/role in virulence } & \multirow[t]{2}{*}{ Reference } \\
\hline & Transcript & Mature & & & \\
\hline \multicolumn{6}{|c|}{ Cladosporium fulvum } \\
\hline Avr2 & 78 & 58 & 8 & Cysteine protease inhibitor & Luderer et al. (2002) \\
\hline Avr4 & 135 & 86 & 8 & Protects against chitinases & Joosten et al. (1994) \\
\hline Avr4E & 121 & 101 & 6 & Unknown & Westerink et al. (2004) \\
\hline Avr9 & 63 & 28 & 6 & Unknown & van den Ackerveken et al. (1992) \\
\hline Ecp1 & 96 & 65 & 8 & Confers fitness advantage & Laugé et al. (1997) \\
\hline Ecp2 & 165 & 143 & 4 & Confers fitness advantage & Laugé et al. (1997) \\
\hline Ecp4 & 119 & 101 & 6 & Unknown & Lauge et al. (2000) \\
\hline Ecp5 & 115 & 98 & 6 & Unknown & Lauge et al. (2000) \\
\hline \multicolumn{6}{|c|}{ Fusarium oxysporum f. sp. lycopersici } \\
\hline Avr1 & 242 & 184 & 6 & Suppression of I-2 and I-3 resistance & Houterman et al. (2008) \\
\hline Avr2 & 163 & 144 & 2 & Required for full virulence & Houterman et al. (2009) \\
\hline Avr3 & 284 & 189 & 8 & Required for full virulence & Rep et al. (2004) \\
\hline \multicolumn{6}{|c|}{ Leptosphaeria maculans } \\
\hline AvrLm1 & 205 & 183 & 1 & Confers fitness advantage & Gout et al. (2006) \\
\hline AvrLm4-7 & 143 & 122 & 8 & Confers fitness advantage & Parlange et al. (2009) \\
\hline AvrLm6 & 144 & 124 & 6 & Unknown & Fudal et al. (2007) \\
\hline \multicolumn{6}{|c|}{ Rhynchosporium secalis } \\
\hline NIP1 & 82 & 60 & 10 & Necrosis-inducing toxin & Rohe et al. (1995) \\
\hline
\end{tabular}

${ }^{\mathrm{A}}$ Number of cysteine resides in the mature protein.

leaf surface - adaxial

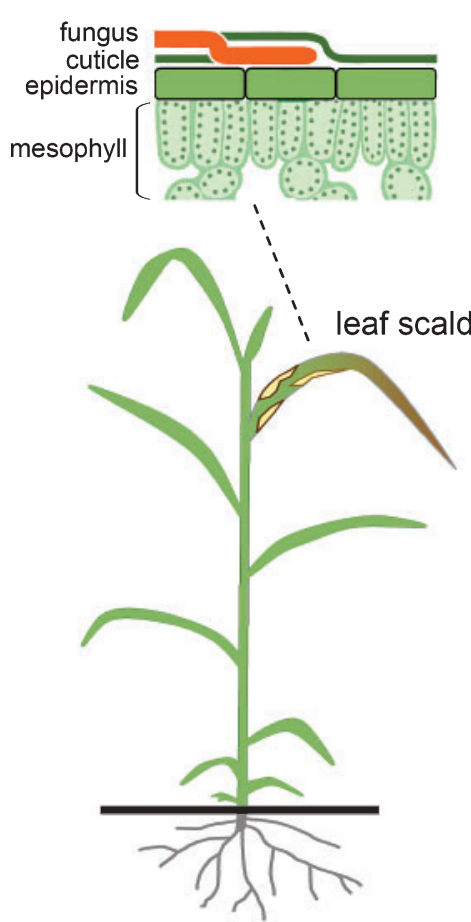

Barley root tissue

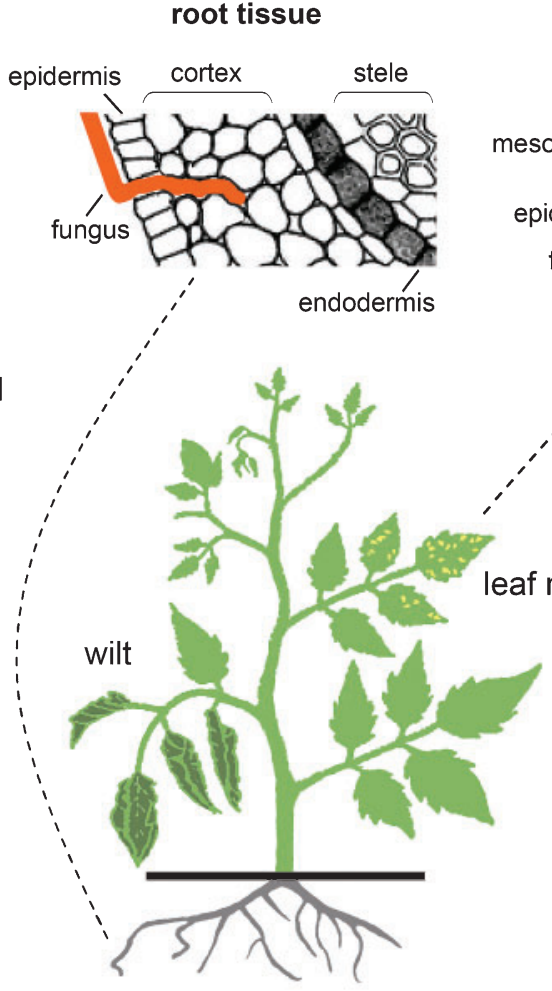

Tomato leaf tissue - abaxial

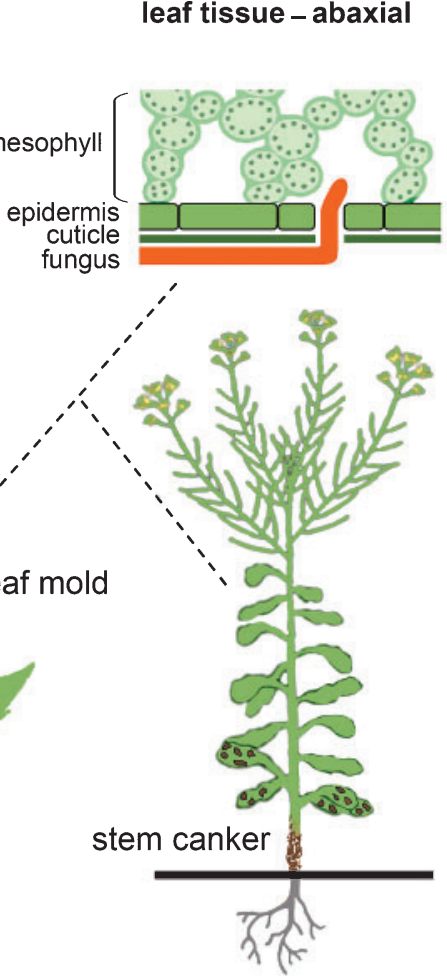

Oilseed rape

Fig. 1. Infection by extracellular fungal pathogens and sites of effector delivery. Routes of fungal entry and pre-sporulation plant disease symptoms are represented for each of the pathosystems presented in this review. (Left) Rhynchosporium secalis grows intercellularly in the subcuticular region of the barley leaf causing scald lesions. (Middle) Fusarium oxysporum $\mathrm{f}$. sp. lycopersici penetrates through the root cortex, and grows within the xylem vessels (not shown), which results in wilt disease on tomato. (Right) Cladosporium fulvum and Leptosphaeria maculans both infect through stomata and grow within the leaf apoplast. During later infection stages, L. maculans grows within the vascular tissue (not shown) towards the crown, causing stem canker on oilseed rape. C. fulvum remains in the apoplast and causes chlorotic spots on tomato, typical of leaf mould disease. 
(MfEcp2) was found to be recognised in tomato $C f-E c p 2$ lines, although, MfEcp2 also caused a reduced disease resistance-like response on lines lacking $C f-E c p 2$ (Stergiopoulos et al. 2010). Two additional effectors, Ecp6 and Ecp 7 have also been identified (Bolton et al.2008), but tomato lines containing a corresponding resistance gene have not yet been reported so these effectors will not be discussed here.

The Avr2, Avr4, Avr4E and Avr9 effectors are recognised in tomato lines carrying $C f-2, C f-4, C f-4 E$ and $C f-9$, respectively (van den Ackerveken et al. 1992; Joosten et al. 1994; Luderer et al. 2002; Westerink et al. 2004). Each of these R genes encodes a membrane-anchored protein with extracellular leucine-rich repeats (LRRs), although the exact recognition mechanisms leading to ETI are not known. Two of these effectors, Avr2 and Avr4, have virulence functions that suppress and avoid host defences, respectively.

Avr2 is a 58 amino acid (aa) cysteine protease inhibitor that inhibits several tomato proteases involved in basal host defence (Rooney et al. 2005; Shabab et al. 2008; van Esse et al. 2008). A virulence function is reinforced by the observation that Arabidopsis expressing Avr2 is more susceptible to the extracellular fungal pathogens Botrytis cinerea and Verticillium dahliae (van Esse et al. 2008). The recognition of Avr2 by the Cf-2 protein is indirect and requires the cysteine protease Rcr3. During infection, Avr2 binds and inhibits Rcr3 and this interaction, which is thought to cause a conformational change to Rcr3, triggers Cf-2-mediated resistance (Rooney et al. 2005). Strains of $C$. fulvum that evade recognition by $\mathrm{Cf}-2$ have altered $A v r 2$ genes containing transposon insertions, gene deletions or mutations encoding amino acid changes (Luderer et al. 2002).

Avr4 is produced as a preproprotein that is both $C$ - and $N$-terminally cleaved after secretion to a mature protein of 86 aa. This effector binds chitin to protect the fungal cell wall against the effects of plant chitinases (van den Burg et al. 2006). Silencing Avr4 significantly reduced C. fulvum virulence, whereas tomato expressing Avr4 is more susceptible to C. fulvum and other fungal pathogens of tomato (van Esse et al. 2007). Most variants of Avr4 that do not trigger Cf-4 resistance have mutations affecting cysteine residues involved in disulfide bonds, resulting in an unstable protein that is more susceptible to proteolysis (van den Burg et al. 2003). Consequently, these unstable variants do not accumulate in the apoplast or elicit ETI, but they do still provide protection against plant chitinases by binding chitin in the fungal cell wall, an association that protects them against degradation by apoplastic proteases (van den Burg et al. 2003). Like Ecp2, a homologue of Avr4 was recently identified in M. fijiensis (MfAvr4), which was also shown to be a functional orthologue (Stergiopoulos et al. 2010). The MfAvr4 protein binds chitin to protect fungal cell walls against plant chitinases and is also recognised in tomato lines carrying $C f-4$. The Avr4 and Ecp2 effectors may therefore represent important proteins required for pathogenicity on a range of hosts.

Avr4E is a 101 aa secreted protein of unknown function. C. fulvum strains virulent on $C f-4 E$ tomato lines have either lost the $A v r 4 E$ gene or have point mutations that encode a stable Avr4E protein with two single amino acid alterations, with only one of these amino acid changes being required to circumvent $\mathrm{Cf}$ -
4E-mediated resistance (Westerink et al. 2004). Avr9 is secreted as a preproprotein that is $C$ - and $N$-terminally cleaved to a mature protein of 28 aa. Avr9 contains three disulfide bridges that form a cysteine knot but, despite structural homology to the carboxypeptidase inhibitor, the function of Avr9 remains unknown (Vervoort et al. 1997; van den Hooven et al. 2001). C. fulvum strains virulent on tomato carrying $C f-9$ lack the $A v r 9$ gene, and $A v r 9$ knockout lines exhibit no loss in virulence (Marmeisse et al. 1993). Avr9 is induced in vitro under low nitrogen conditions and is regulated by the Nrfl gene (PérezGarcía et al. 2001). Nrfl knockouts show reduced virulence on susceptible tomato, but are still avirulent on $C f-9$ plants, suggesting Nrf1 is not the only regulator of Avr9. No other $A v r$ or Ecp effector genes are induced under nitrogen-limiting conditions and their regulators are currently unknown (Thomma et al. 2006).

\section{Fusarium oxysporum $f$. sp. lycopersici}

The soil-borne fungal pathogen Fusarium oxysporum f. sp. lycopersici $(\mathrm{Fol})$ infects roots of tomato plants via wounds or by direct penetration and colonises xylem vessels causing wilt disease (Fig. 1). Seven proteins have been isolated from xylem sap during Fol infection - termed secreted in xylem (Six) proteins. The recent genome sequencing of Fol has revealed that the SIX genes are all located on the same chromosome, which is absent from non-pathogenic $F$. oxysporim (Ma et al. 2010). This chromosome was experimentally shown to be responsible for pathogenicity on tomato by transferring it to a non-pathogenic strain, converting it to a pathogen (Ma et al. 2010). Three Six proteins function as Avr determinants in tomato cultivars carrying the corresponding $\mathrm{R}$ genes. After secretion, Avr3 (Six1) is cleaved at both the $N$ - and $C$-terminus to yield a $22 \mathrm{kDa}(189$ aa) protein and a $12 \mathrm{kDa}$ derivative, the former being the form thought to trigger resistance in tomato cultivars carrying the $I-3$ resistance gene (Rep et al. 2004; M. Rep, pers. comm.). Expression of Avr3 requires the presence of living plant cells and occurs immediately upon penetration of the root cortex (van der Does et al. 2008). The exact function of this effector is currently not known; however, it is required for full virulence and a loss of $A v r 3$ causes a significant fitness penalty (Rep et al. 2005). Accordingly, all natural Fol isolates contain Avr3 and no sequence variants that overcome $I-3$ recognition have been found (Rep et al. 2004, 2005). Nonetheless, Fol isolates virulent on $I-3$ cultivars do exist and overcome resistance by the presence of a second effector protein, Avr1, which inhibits I-3-mediated resistance (Houterman et al. 2008).

The Avr2 (Six3) effector is 144 aa and contains just two cysteine residues (cf. other effectors, see Table 1). The cognate $I-2$ gene, currently the only Fol resistance gene to be cloned, encodes an intracellular nucleotide-binding leucine-rich repeat (NB-LRR) protein with an $\mathrm{N}$-terminal coiled coil (CC) domain (Simons et al. 1998). Recognition of Avr2 occurs inside the plant cell (Houterman et al. 2009), consistent with the location of I-2, although it is not known whether these two proteins directly interact. Furthermore, an intracellular recognition implies that Avr2 is translocated from the xylem into the host cell, a feature that is common to effectors from biotrophic fungi and oomycetes that penetrate the host cell wall and form membrane-invaginating 
feeding structures (Catanzariti et al. 2007; Panstruga and Dodds 2009). Avr2 is also required for full virulence in susceptible hosts and no isolates have been found with deletions of the $A v r 2$ gene. Variants of Avr2 carrying single amino acid changes have been found that circumvent I-2-mediated resistance with no apparent fitness cost (Houterman et al. 2009). Nonetheless, inhibition of I2-mediated resistance, also mediated by Avr1, is a more frequent mechanism underlying virulence on $I-2$ cultivars (Houterman et al. 2008).

Avr1 (Six4) is processed after secretion and is present in the xylem sap as a 184 aa mature protein (Houterman et al. 2008). Fol strains carrying Avr1 trigger a resistance response in tomato cultivars carrying either the $I$ or the $I-1$ gene but is not required for virulence on plants lacking the cognate $I$ genes (Houterman et al. 2008). Conversely, on $I-2$ and $I-3$, plants, Avr1 functions as an inhibitor of ETI, although the mechanism of this inhibition is not yet known. No variation in the Avr1 sequence has been detected among different $\mathrm{Fol}$ isolates and the $\mathrm{Avrl}$ gene is absent from strains avirulent on $I-2$ or $I-3$ plants (Houterman et al. 2008).

\section{Leptosphaeria maculans}

The stem canker fungus Leptosphaeria maculans causes blackleg disease on brassicas (Fig. 1). During the symptomless phase of the disease, the fungus penetrates the leaf through stomatal openings and grows within the mesophyll layer before entering the vascular tissue and moving into the base of the stem. Map-based cloning has been used to identify three L. maculans avirulence genes, AvrLm1 (Gout et al. 2006), AvrLm6 (Fudal et al. 2007) and AvrLm4-7 (Parlange et al. 2009), which are recognised by yet to be isolated $\mathrm{Rlm}$ resistance genes in oilseed rape (Brassica napus L.). All three $A v r$ genes encode small proteins with predicted signal peptides and have similar expression profiles, with the highest level of expression seen during leaf infection and a low level of expression in vitro (Fudal et al. 2007; Parlange et al. 2009). Unlike AvrLm6 and AvrLm4-7, AvrLm1 contains only one cysteine residue and, therefore, may be targeted to the cytosol of the host cell, analogous to Fol Avr2 and the cysteine-poor effectors from biotrophic fungi and oomycetes that are known to enter host cells (Catanzariti et al. 2007). Most isolates that have overcome Rlm1-mediated resistance carry a deletion of the AvrLm1 gene (Gout et al. 2007). Nevertheless, a measurable fitness cost has been reported for virulence alleles at the AvrLm1 locus, suggesting that this effector does have a virulence function (Huang et al. 2010). Similarly, a significant fitness advantage is associated with an intact AvrLm4-7 gene suggesting that the AvrLm4-7 effector also has a virulence function (Balesdent et al. 2006; Huang et al. 2006, 2010). This effector confers avirulence on both $R \operatorname{lm} 4$ and $R \operatorname{lm} 7$ B. napus lines, and appears to have dual recognition specificity. Evaluation of natural isolates virulent on B. napus carrying $R \operatorname{lm} 4$ or $R \operatorname{lm} 7$ found that evasion of $R \operatorname{lm} 7$ mediated resistance was associated with deletion of the AvrLm4-7 gene, whereas evasion of Rlm4-mediated resistance was frequently the result of a single amino acid change in the AvrLm4-7 protein, suggesting different recognition mechanisms (Parlange et al. 2009). However, this amino acid change is also associated with a reduced fitness (Parlange et al. 2009).

\section{Rhynchosporium secalis}

The fungus Rhynchosporium secalis is the causal agent of leaf scald on barley (Fig. 1). After penetrating the cuticle, $R$. secalis grows intercellularly in the subcuticular region of the host leaf where it secretes three small proteins that function as non-specific toxins (Wevelsiep et al. 1991). These proteins were purified from fungal culture filtrates and when injected into the leaves of barley and other non-host cereals, these toxins, termed necrosisinducting proteins (NIP), cause scald-like lesions. NIP1 has a stimulatory effect on the host's plasma membrane $\mathrm{H}^{+}$-ATPase, which is the likely cause of leaf necrosis (Wevelsiep et al. 1993) and is also an avirulence determinant, activating ETI in barley cultivars carrying the Rrs 1 resistance gene (Hahn et al. 1993; Rohe et al. 1995). NMR spectrometry has revealed a novel protein fold with five disulfide bridges that make NIP1 highly stable (van't Slot et al. 2003). Most races of R. secalis virulent on Rrs 1 cultivars lack the Nipl gene, but some have alleles with point mutations that generate amino acid changes (Schürch et al. 2004). Sequence variants of this effector, which do not induce Rrs 1-mediated resistance, also lack necrosis-inducing activity, suggesting that NIP1 function and Rrs1 recognition are inherently linked. Furthermore, NIP1 binds a single plasma membrane receptor, found in susceptible and resistant cultivars, which mediates both necrosis and Rrs 1 -dependent resistance (van't Slot et al. 2007).

\section{Concluding remarks}

The identification of numerous novel secreted effector proteins from extracellular fungal pathogens suggests they conduct diverse functions during infection. The presence of even numbers of cysteine residues and their occurrence in intercellular wash fluids suggests these effectors function outside the host cell. Indeed, this is true for the C. fulvum effectors Avr2 and Avr4, which inhibit plant apoplastic proteases and bind chitin, respectively. However, this may not be the case for all effectors, particularly AvrLm1, which has only one cysteine residue and would, therefore, be vulnerable to apoplastic proteases, and the Fol effector Avr2, which only has two cysteine reidues and activates ETI from inside the plant cell. It is also possible that the Fol effector Avr1 functions within host cells as this effector inhibits I-2mediated resistance triggered by Avr2, although the nature of this inhibition is not known and could act outside the cell to prevent Avr2 uptake. The discovery of fungal effectors that negate plant defences, and the fact that many other effectors have a virulence function, highlights effectors as key components in pathogenicity. Thus, identifying complete pathogen secretomes along with functional studies and the identification of host targets will significantly advance our knowledge of the molecular mechanisms pathogens use to manipulate plant cells to facilitate colonisation and ultimately cause disease. Furthermore, understanding how recognition of effectors by cognate $\mathrm{R}$ proteins can be compromised is important not only for understanding the evolution of pathogenicity and plant resistance but also the durability of $\mathrm{R}$ genes. As a more complete picture of the molecular mechanisms involved in R-Avr interactions is gathered, better approaches to the use of $\mathrm{R}$ genes in the field and the development 
of novel disease control mechanisms will undoubtedly become apparent.

\section{References}

Balesdent MH, Louvard K, Pinochet X, Rouxel T (2006) A large-scale survey of races of Leptosphaeria maculans occurring on oilseed rape in France. European Journal of Plant Pathology 114, 53-65. doi:10.1007/s10658005-2104-0

Bolton MD, van Esse HP, Vossen JH, de Jonge R, Stergiopoulos I, et al. (2008) The novel Cladosporium fulvum lysin motif effector Ecp6 is a virulence factor with orthologues in other fungal species. Molecular Microbiology 69, 119-136. doi:10.1111/j.1365-2958.2008.06270.x

Caplan J, Padmanabhan M, Dinesh-Kumar SP (2008) Plant NB-LRR immune receptors: from recognition to transcriptional reprogramming. Cell Host \& Microbe 3, 126-135. doi:10.1016/j.chom.2008.02.010

Catanzariti AM, Dodds PN, Ellis JG (2007) Avirulence proteins from haustoria-forming pathogens. FEMS Microbiology Letters 269, 181-188. doi:10.1111/j.1574-6968.2007.00684.x

de Kock MJD, Brandwagt BF, Bonnema G, de Wit PJGM, Lindhout P (2005) The tomato Orion locus comprises a unique class of $\mathrm{Hcr} 9$ genes. Molecular Breeding 15, 409-422. doi:10.1007/s11032-005-0386-8

Fudal I, Ross S, Gout L, Blaise F, Kuhn ML, et al. (2007) Heterochromatinlike regions as ecological niches for avirulence genes in the Leptosphaeria maculans genome: map-based cloning of AvrLm6. Molecular PlantMicrobe Interactions 20, 459-470. doi:10.1094/MPMI-20-4-0459

Gout L, Fudal I, Kuhn ML, Blaise F, Eckert M, et al. (2006) Lost in the middle of nowhere: the AvrLml avirulence gene of the Dothideomycete Leptosphaeria maculans. Molecular Microbiology 60, 67-80. doi:10.1111/j.1365-2958.2006.05076.x

Gout L, Kuhn ML, Vincenot L, Bernard-Samain S, Cattolico L, et al. (2007) Genome structure impacts molecular evolution at the AvrLm1 avirulence locus of the plant pathogen Leptosphaeria maculans. Environmental Microbiology 9, 2978-2992. doi:10.1111/j.1462-2920.2007.01408.x

Hahn M, Jungling S, Knogge W (1993) Cultivar-specific elicitation of barley defense reactions by the phytotoxic peptide NIP1 from Rhynchosporium secalis. Molecular Plant-Microbe Interactions 6, 745-754.

Houterman PM, Cornelissen BJ, Rep M (2008) Suppression of plant resistance gene-based immunity by a fungal effector. PLoS Pathogens 4, e1000061. doi:10.1371/journal.ppat.1000061

Houterman PM, Ma L, van Ooijen G, de Vroomen MJ, Cornelissen BJ, et al. (2009) The effector protein Avr2 of the xylem colonizing fungus Fusarium oxysporum activates the tomato resistance protein I-2 intracellularly. The Plant Journal 58, 970-978. doi:10.1111/j.1365313X.2009.03838.X

Huang YJ, Li ZQ, Evans N, Rouxel T, Fitt BDL, et al. (2006) Fitness cost associated with loss of the AvrLm4 avirulence function in Leptosphaeria maculans (phoma stem canker of oilseed rape). European Journal of Plant Pathology 114, 77-89. doi:10.1007/s10658005-2643-4

Huang YJ, Balesdent MH, Li ZQ, Evans N, Rouxel T, et al. (2010) Fitness cost of virulence differs between the AvrLml and AvrLm4 loci in Leptosphaeria maculans (phoma stem canker of oilseed rape). European Journal of Plant Pathology 126, 279-291. doi:10.1007/ s10658-009-9539-7

Joosten MHAJ, Cozijnsen TJ, de Wit PJGM (1994) Host resistance to a fungal tomato pathogen lost by a single base-pair change in an avirulence gene. Nature 367, 384-386. doi:10.1038/367384a0

Laugé R, Joosten MHAJ, van den Ackerveken GFJM, van den Broek HWJ, de Wit PJGM (1997) The in planta-produced extracellular proteins ECP1 and ECP2 of Cladosporium fulvum are virulence factors. Molecular Plant-Microbe Interactions 10, 725-734. doi:10.1094/MPMI. 1997.10.6.725
Lauge R, Goodwin PH, de Wit PJGM, Joosten MHAJ (2000) Specific HRassociated recognition of secreted proteins from Cladosporium fulvum occurs in both host and non-host plants. The Plant Journal 23, 735-745. doi:10.1046/j.1365-313x.2000.00843.x

Luderer R, Takken FL, de Wit PJGM, Joosten MHAJ (2002) Cladosporium fulvum overcomes $C f$-2-mediated resistance by producing truncated AVR2 elicitor proteins. Molecular Microbiology 45, 875-884. doi:10.1046/j.1365-2958.2002.03060.x

Ma LJ, van der Does HC, Borkovich KA, Coleman JJ, Daboussi MJ, et al. (2010) Comparative genomics reveals mobile pathogenicity chromosomes in Fusarium. Nature 464, 367-373. doi:10.1038/nature 08850

Marmeisse R, van den Ackerveken GFJM, Goosen T, de Wit PJGM, van den Broek HWJ (1993) Disruption of the avirulence gene $a v r 9$ in 2 races of the tomato pathogen Cladosporium fulvum causes virulence on tomato genotypes with the complementary resistance gene Cf9. Molecular Plant-Microbe Interactions 6, 412-417.

Panstruga R, Dodds PN (2009) Terrific protein traffic: the mystery of effector protein delivery by filamentous plant pathogens. Science 324, 748-750. doi:10.1126/science. 1171652

Parlange F, Daverdin G, Fudal I, Kuhn ML, Balesdent MH, et al. (2009) Leptosphaeria maculans avirulence gene AvrLm4-7 confers a dual recognition specificity by the $R \operatorname{lm} 4$ and $R \operatorname{lm} 7$ resistance genes of oilseed rape, and circumvents Rlm4-mediated recognition through a single amino acid change. Molecular Microbiology 71, 851-863. doi:10.1111/j.1365-2958.2008.06547.x

Pérez-García A, Snoeijers SS, Joosten MHAJ, Goosen T, de Wit PJGM(2001) Expression of the avirulence gene Avr 9 of the fungal tomato pathogen Cladosporium fulvum is regulated by the global nitrogen response factor NRF1. Molecular Plant-Microbe Interactions 14, 316-325. doi:10.1094/ MPMI.2001.14.3.316

Rep M, van der Does HC, Meijer M, van Wijk R, Houterman PM, et al. (2004) A small, cysteine-rich protein secreted by Fusarium oxysporum during colonization of xylem vessels is required for I-3-mediated resistance in tomato. Molecular Microbiology 53, 1373-1383. doi:10.1111/j.13652958.2004.04177.x

Rep M, Meijer M, Houterman PM, van der Does HC, Cornelissen BJ (2005) Fusarium oxysporum evades I-3-mediated resistance without altering the matching avirulence gene. Molecular Plant-Microbe Interactions $\mathbf{1 8}$, 15-23. doi:10.1094/MPMI-18-0015

Rohe M, Gierlich A, Hermann H, Hahn M, Schmidt B, et al. (1995) The racespecific elicitor, NIP1, from the barley pathogen, Rhynchosporium secalis, determines avirulence on host plants of the Rrs 1 resistance genotype. The EMBO Journal 14, 4168-4177.

Rooney HCE, van't Klooster JW, van der Hoorn RAL, Joosten MHAJ, Jones JDG, et al. (2005) Cladosporium Avr2 inhibits tomato Rcr3 protease required for $C f$-2-dependent disease resistance. Science 308, 1783-1786. doi:10.1126/science.1111404

Schürch S, Linde CC, Knogge W, Jackson LF, McDonald BA (2004) Molecular population genetic analysis differentiates two virulence mechanisms of the fungal avirulence gene NIP1. Molecular PlantMicrobe Interactions 17, 1114-1125. doi:10.1094/MPMI.2004.17. 10.1114

Shabab M, Shindo T, Gu C, Kaschani F, Pansuriya T, et al. (2008) Fungal effector protein AVR2 targets diversifying defense-related Cys proteases of tomato. The Plant Cell 20, 1169-1183. doi:10.1105/ tpc. 107.056325

Simons G, Groenendijk J, Wijbrandi J, Reijans M, Groenen J, et al. (1998) Dissection of the Fusarium I2 gene cluster in tomato reveals six homologs and one active gene copy. The Plant Cell 10, 1055-1068.

Stergiopoulos I, de Kock MJD, Lindhout P, de Wit PJGM (2007) Allelic variation in the effector genes of the tomato pathogen Cladosporium fulvum reveals different modes of adaptive evolution. Molecular PlantMicrobe Interactions 20, 1271-1283. doi:10.1094/MPMI-20-10-1271 
Stergiopoulos I, van den Burg HA, Ökmen B, Beenen HG, van Liere S, et al. (2010) Tomato Cf resistance proteins mediate recognition of cognate homologous effectors from fungi pathogenic on dicots and monocots. Proceedings of the National Academy of Sciences of the United States of America 107, 7610-7615. doi:10.1073/pnas. 1002910107

Thomma BPHJ, Bolton MD, Clergeot PH, de Wit PJGM (2006) Nitrogen controls in planta expression of Cladosporium fulvum Avr 9 but no other effector genes. Molecular Plant Pathology 7, 125-130. doi:10.1111/ j.1364-3703.2006.00320.x

van den Ackerveken GFJM, van Kan JA, de Wit PJGM (1992) Molecular analysis of the avirulence gene avr9 of the fungal tomato pathogen Cladosporium fulvum fully supports the gene-for-gene hypothesis. The Plant Journal 2, 359-366. doi:10.1046/j.1365-313X.1992.t01-3400999.x

van den Burg HA, Westerink N, Francoijs KJ, Roth R, Woestenenk E, et al. (2003) Natural disulfide bond-disrupted mutants of AVR4 of the tomato pathogen Cladosporium fulvum are sensitive to proteolysis, circumvent Cf-4-mediated resistance, but retain their chitin binding ability. Journal of Biological Chemistry 278, 27 340-27 346. doi:10.1074/jbc.M212196200

van den Burg HA, Harrison SJ, Joosten MHAJ, Vervoort J, de Wit PJGM (2006) Cladosporium fulvum Avr4 protects fungal cell walls against hydrolysis by plant chitinases accumulating during infection. Molecular Plant-Microbe Interactions 19, 1420-1430. doi:10.1094/ MPMI-19-1420

van der Does HC, Duyvesteijn RGE, Goltstein PM, van Schie CCN, Manders EMM, et al. (2008) Expression of effector gene SIX1 of Fusarium oxysporum requires living plant cells. Fungal Genetics and Biology 45, 1257-1264. doi:10.1016/j.fgb.2008.06.002

van den Hooven HW, van den Burg HA, Vossen P, Boeren S, de Wit PJGM, et al. (2001) Disulfide bond structure of the AVR9 elicitor of the fungal tomato pathogen Cladosporium fulvum: evidence for a cystine knot. Biochemistry 40, 3458-3466. doi:10.1021/bi0023089

van Esse HP, Bolton MD, Stergiopoulos I, de Wit PJGM, Thomma BPHJ (2007) The chitin-binding Cladosporium fulvum effector protein Avr4 is a virulence factor. Molecular Plant-Microbe Interactions 20, 1092-1101. doi:10.1094/MPMI-20-9-1092 van Esse HP, Van't Klooster JW, Bolton MD, Yadeta KA, van Baarlen P, etal. (2008) The Cladosporium fulvum virulence protein Avr2 inhibits host proteases required for basal defense. The Plant Cell 20, 1948-1963. doi:10.1105/tpc. 108.059394

van't Slot KAE, van den Burg HA, Kloks C, Hilbers CW, Knogge W, et al. (2003) Solution structure of the plant disease resistance-triggering protein NIP1 from the fungus Rhynchosporium secalis shows a novel betasheet fold. The Journal of Biological Chemistry 278, 45 730-45736. doi:10.1074/jbc.M308304200

van't Slot KAE, Gierlich A, Knogge W (2007) A single binding site mediates resistance- and disease-associated activities of the effector protein NIP1 from the barley pathogen Rhynchosporium secalis. Plant Physiology 144, 1654-1666. doi:10.1104/pp.106.094912

Vervoort J, van den Hooven HW, Berg A, Vossen P, Vogelsang R, et al. (1997) The race-specific elicitor AVR9 of the tomato pathogen Cladosporium fulvum: a cystine knot protein. Sequence-specific $1 \mathrm{H}$ NMR assignments, secondary structure and global fold of the protein. FEBS Letters 404, 153-158. doi:10.1016/S0014-5793(97)00117-8

Westerink N, Brandwagt BF, de Wit PJGM, Joosten MHAJ (2004) Cladosporium fulvum circumvents the second functional resistance gene homologue at the $C f-4$ locus (Hcr $9-4 E$ ) by secretion of a stable avr4E isoform. Molecular Microbiology 54, 533-545. doi:10.1111/ j.1365-2958.2004.04288.x

Wevelsiep L, Kogel KH, Knogge W (1991) Purification and characterization of peptides from Rhynchosporium secalis inducing necrosis in barley. Physiological and Molecular Plant Pathology 39, 417-482.

Wevelsiep L, Rupping E, Knogge W (1993) Stimulation of barley plasmalemma $\mathrm{H}^{+}$-ATPase by phytotoxic peptides from the fungal pathogen Rhynchosporium secalis. Plant Physiology 101, 297-301.

Manuscript received 7 April 2010, accepted 15 May 2010 